\title{
Journal of Surgery
}

Puentes PS, et al. J Surg: JSUR-1170.

\section{Case Report}

DOI: $10.29011 / 2575-9760.001170$

\section{Deep Lipoma of the Right Hand: Case Presentation}

\section{Pavel Sánchez Puentes ${ }^{1 *}$, Olga Caridad Leòn Gonzàlez ${ }^{2}$, Pedro Rolando Lòpez Rodrìguez ${ }^{3}$, Jorge Satorre Rocha ${ }^{2}$, Luis Manuel Danta Fundora ${ }^{4}$}

'First Degree Specialist in Orthopedics and Traumatology Intructor Professor, General Teaching Hospital "Enrique Cabrera", Havana, Cuba

${ }^{2}$ First Degree Specialist in General Surgery and Auxiliary Professor in General Surgery, General Teaching Hospital "Enrique Cabrera", Havana, Cuba

${ }^{3}$ Specialist of First and Second Degree in General Surgery and Auxiliary Professor in General Surgery, General Teaching Hospital "Enrique Cabrera", Havana, Cuba

${ }^{4}$ First Degree Specialist in General Surgery and Instructor Professor, General Teaching Hospital "Enrique Cabrera”, Havana, Cuba

"Corresponding author: Pavel Sánchez Puentes, First Degree Specialist in Orthopedics and Traumatology Intructor Professor, General Teaching Hospital “Enrique Cabrera”, Havana, Cuba. Email: pavel.sanchez@infomed.sld.cu

Citation: Puentes PS, Gonzàlez OCL, Rodrìguez PRL, Rocha JS, Fundora LMD (2018) Deep Lipoma of the Right Hand: Case Presentation. J Surg: JSUR-1170. DOI: 10.29011/2575-9760. 001170

Received Date: 11 September, 2018; Accepted Date: 14 September, 2018; Published Date: 19 September, 2018

\section{Abstract}

Benign tumors derived from adipose tissue are probably the most common in the clinic. The most common of these is the subcutaneous lipoma, which practically does not cause any type of functional disorder or diagnostic problem. However, there are other types of lipomas of subfascial localization (deep lipomas), much less frequent, which can be symptomatic and, above all, can raise serious doubts in their diagnosis. Lipomas account for $16 \%$ of soft tissue tumors that originate in the hand. They have a particular clinical presentation due to the anatomical and functional complexity of the area. We present a case, attended in our service, male of 35 years of age with tumor on the level of the tenar region of the right hand that extended towards the first interdigital space for his palmar and dorsal face, of approximately one year of evolution, with slight difficulty for the digital clamp, although its main concern was cosmetics. Imaging and anatomopathological preoperative studies were performed, the surgical treatment was the excision of the tumor and the definitive diagnosis was made by biopsy of the surgical piece.

Keywords: Hand Surgery; Lipoma; Soft Tissue Tumor

\section{Introduction}

Almost every day, patients with some type of protuberance under the skin come to the General Surgery office in the space that specialists call Subcutaneous Cell Tissue, a tissue composed mainly of connective tissue (collagen) and fat that occupies the space between the skin and deep planes like muscles and tendons. The masses that develop in this space can be very diverse due to the different types of tissue and cells that coexist in the area (adipocytes, smooth muscle, fibroblasts, nerves, etc.). However, the vast majority of these lesions are confirmed. as lipomas after the anatomopathological study. A lipoma is no more than the growth of an island of adipose tissue (fat) well delimited healthy surrounding tissue which tends to grow locally without invading adjacent tissue spaces or send cells at a distance, in essence it is a tumor benign that tends to grow locally without generating risk for the indemnity of neighboring structures or for the life of the patient. The presence of a lipoma is suspected whenever there is a localized mass in subcutaneous cellular tissue, usually well defined, variable in size (ranging from $5 \mathrm{~mm}$ to $10 \mathrm{~cm}$ ), soft, mobile and in most cases asymptomatic; ultrasound (echo of soft tissues) helps to specify the diagnosis when a mass is seen surrounded by a capsule whose echo graphic characteristics are similar to that of he is surrounding fatty tissue. Despite the clinical orientation, the definitive diagnosis of a lipoma is always the pathological anatomy (biopsy) usually of the lesion extracted in its entirety in order to be able to establish the differential diagnosis with other similar lesions (fibrolipomas, liposarcomas) which is not It can be established through the use of other biopsy techniques such as Puncture by Fine Needle (FNAB) or Trucut Biopsy.

Once the diagnosis of pathological anatomy of a lipoma is received, the patient can remain calm since the lesion itself does not represent any risk to his health and once it has been removed the 
patient can be considered cured; Special mention should be made of those patients suffering from Multiple Familial Lipomatosis condition where in spite of extracting the one or the lipomas there may be recurrences (they reappear) in the same place or in another anatomical location; multiple familial lipomatosis represents more an inconvenience for the patient than a risk to their health although association with other systemic pathologies such as Neurofibromatosis or Multiple Neoplasia Syndrome should be ruled out; If this association exists, it is necessary to channel the case according to the corresponding management protocol. When the pathology reports. Liposarcoma (malignant variety of the Lipoma) may need to perform an expansion of surgical margins and sometimes supplement with local radiotherapy in order to avoid local recurrence, invasion of adjacent tissue and distant metastasis. In general, more than $90 \%$ of lipomas will be benign and can be resolved with surgeries of greater or lesser complexity depending on size and location, even so the presence of a soft tissue tumor should never be underestimated since if not studied and treated A diagnosis of malignant disease could be overlooked, which in that case would endanger the life of the patient [1].

\section{Clinical Case}

This is a patient of a 36-year-old patient with a previous health history who has noticed a volume increase in the right hand for about a year, which causes slight difficulty in performing the digital clamp and the main concern is cosmetic Physical examination: A tumor is observed and palpated in the thenar region of the right hand with $\mathrm{x}$ tension to the first interdigital space by its dorsal and palmar face [2]. Complementary exams Hematology: Hb. 12.4 g / 1, glycemia .5.1, coagulogram.normal, creatinine $. \mu \mathrm{mol} / \mathrm{L}$, erythrosedimentation. $5 \mathrm{~mm}$ h (Figures 1-4) IMAGING EXAMS.

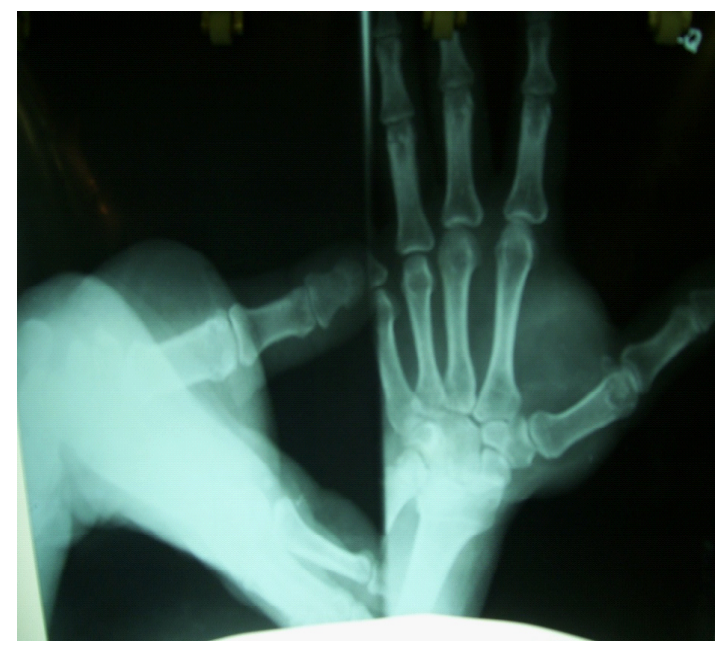

Figure 1: Radiological study of the right hand. Surgical treatment.

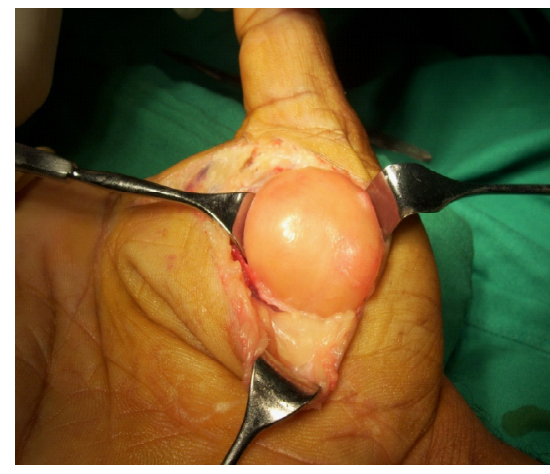

Figure 2: Exposure of the lipomatous tumor.

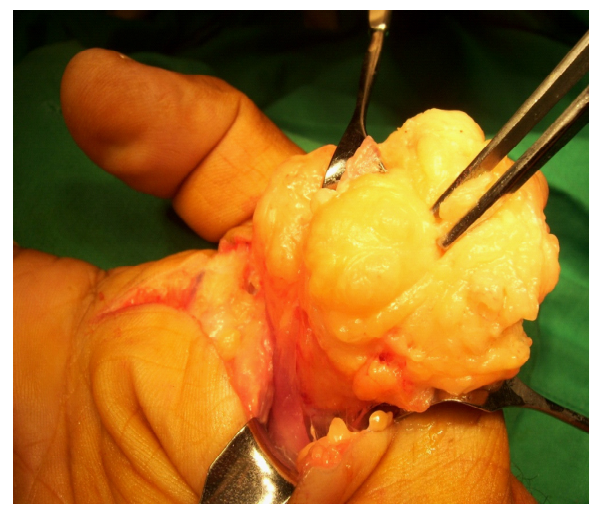

Figure 3: Lipomatous dissected tumor.

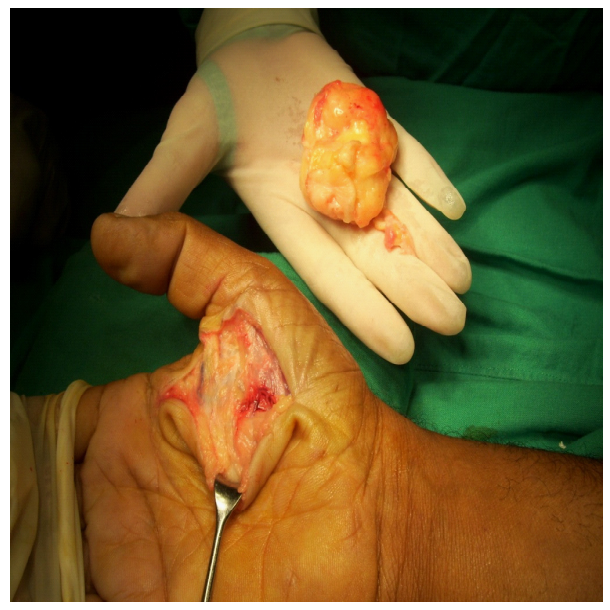

Figure 4: The exeresis of the lipoma is completed.

Histopathological study. Biopsy was performed by aspiration with a fine needle, prior to the operation and after the operation the piece was sent to the anatomopathological deparatment and the difinitive diagnosis of the urgical piece is: adult fat cells, not atypical cell. Evolution:Satisfactory: functional as a cosmetic 4 months after surgery. 


\section{Discussion}

According to Dequeker, et al [1]. the "Mona Lisa", a famous painting made between 1503 and 1506, presents a lipoma on the back of the left hand and a xanthelasma on the right upper eyelid, which would indicate that this lesion was already well known first description attributed to Addison and Gall in 18512. The lipoma (L) is a mesenchymal tumor that occupies the first place in frequency among soft tissue tumors, which varies, according to different authors, between 16 to 50\%. It represents, in turn, $1 \%$ of benign tumors [3]. It usually appears after 20 years of age, being a very rare finding in children. Its greatest presentation in the female sex is cited, which many attribute to the consultation for aesthetic reasons.

Lipomatosis: this termis usuallyused to designate that situation of $\mathrm{L}$ in multiple forms, when its meaning is reserved, in a stricter form, to that tumor proliferation of fatty tissue that appears uncapped. The L are asymptomatic masses, symmetrical, slow-growing, of regular shape and rounded to ovoid or discoid, pasty or cystic consistency, usually lobed surface. They have good mobility and can lead to the formation of dimples on the surface when exercising their passive movement. The consistency may increase after the application of ice, a maneuver used in certain occasions to favor its diagnosis. For some authors, the skin that covers them, always normal, is colder than the surrounding skin, a fact that has not been highly valued or explored. The palpation is painless and when there is a feeling of discomfort, it is due to compression of peripheral nerves or special varieties of the same tumor. It has also been postulated its most common presence in obese individuals, although significant weight loss does not reduce the size of lipomas. They grow slowly or are stationed, but any sudden variation in it must alert us to its malignant transformation, an event that is considered very rare and / or denied in opportunities [4]. Likewise, its spontaneous regression is extremely infrequent. By means of immunostaining it was possible to demonstrate that in normal tissue there are two types of Lipoprotein Lipase (LPL): a partially sensitive one of $55 \mathrm{KDa}$ and a totally sensitive one of $52 \mathrm{KDa}$. In the $\mathrm{L}$ there is greater secretion of partially sensitive subunits and therefore greater activity [5]. Molecular biology shows that in some L and other benign mesenchymal tumors, there is fusion, truncation or transcriptional activation of HMGA2 gene (high mobility group A2) a family of architectural transcription factors. The recombination of $12 \mathrm{q} 13-\mathrm{q} 15$ chromosomal segments with other chromosomal bands has been reported in these lesions. The translocation HMGA2 / LPP gene (lipoma preferred partner) is the most frequently found [6]. Recently, chromosomal translocations, karyotype alterations associated with them, have been published [5-7].

\section{References}

1. Huczak L, Dibran NE (2007) Lripoma y Lipomatosis. Rev argent dermatol 88 .

2. Segal P, Insull W, Chambless LE, Stinnett S, LaRosa JC, et al. (1986) The association of dislipoproteinemia with corneal arcus and xanthelasma. The lipi Research Clinics Program Prevalence Study. Circulation 73: 108-118.

3. Fuchs A, Henrot P, Walter. Tumores lipomatosos de partes blandas de miembros y de articulaciones en el adulto.

4. McKee P (1996) Pathology of the skin. Segunda Edición. Editorial Mosby-Wolfe London. Wiesbaden. Alemania. 1996.

5. Park JW, Yang JY, Rhee, et al. (1996) Horm Metab Re 28: 7-10.

6. Nilsson M, Mertens F, Hoglund M, et al. (2006) Cytogenet Genome Res 112: 60-66.

7. Enzinger FM, Weiss SW (1995) Soft Tissue Tumors. Tercera Edición. Editorial Mosby. St Louis. Toronto. Canadá 1995. 